\title{
Can plant functional traits explain shifts in community composition in a changing Arctic? ${ }^{1}$
}

\author{
Katlyn R. Betway-May, Robert D. Hollister, Jeremy L. May, Jacob A. Harris, \\ William A. Gould, and Steven F. Oberbauer
}

\begin{abstract}
The Arctic is warming twice as fast as the rest of the globe. Graminoid, deciduous shrub, and evergreen shrub cover has increased in some regions, but not others. To better understand why plant responses vary across regions, we compared change in plant cover over time with nine functional traits of 12 dominant species in three regions of northern Alaska (Utqiagivik, Atqasuk, and Toolik Lake). Cover was measured three times from 2008 to 2018. Repeated-measures analysis of variance (ANOVA) found that one species - Carex aquatilis - showed significant change in cover over time, increasing by $12.7 \%$ at Atqasuk. Canonical correspondence analysis suggested a relationship between shifts in species cover and traits, but Pearson and Spearman rank correlations did not find a significant trend for any trait when analyzed individually. Investigation of community-weighted means (CWMs) for each trait revealed no significant changes over time for any trait in any region. By comparison, estimated ecosystem values for several traits important to ecosystem functioning showed consistent increases over time in two regions (Utqiagivik and Atqasuk). Our results indicate that vascular plant community composition and function have remained consistent over time; however, documented increases in total plant cover have important implications for ecosystem functioning.

Key words: tundra, vegetation change, plant functional trait, latitudinal gradient, communityweighted mean (CWM).

Résumé : L’Arctique se réchauffe plus de deux fois plus que la moyenne mondiale. Il a été démontré que les graminoïdes, les arbustes à feuilles caduques et les arbustes à feuilles persistantes augmentent leur couverture dans certaines régions, mais pas dans d'autres. Pour mieux comprendre pourquoi la réponse des plantes varie d'une région à l'autre, les auteurs ont comparé les changements de couverture dans le temps avec neuf traits fonctionnels de douze espèces dominantes dans trois régions du nord de l'Alaska (Utqiagivik, Atqasuk et Toolik Lake). La couverture a été mesurée trois fois de 2008 à 2018. L’ANOVA à mesures répétées a révélé qu'une espèce présentait un changement significatif de la couverture au fil du temps : Carex aquatilis a augmenté à Atqasuk de 12,7\%. L'analyse canonique des correspondances a suggéré une relation entre les changements de couverture des espèces et les traits, mais les corrélations de Pearson et de Spearman n’ont pas trouvé de tendance
\end{abstract}

\footnotetext{
Received 24 September 2020. Accepted 29 April 2021.

K.R. Betway-May, R.D. Hollister,* and J.A. Harris. Department of Biology, Grand Valley State University, 1 Campus Drive, Allendale, MI 49401, USA.

J.L. May* and S.F. Oberbauer. Department of Biological Sciences, Florida International University, 11200 SW 8th Street, Miami, FL 33199, USA.

W.A. Gould. International Institute of Tropical Forestry, USDA Forest Service, 1201 Calle Ceiba, Río Piedras, PR 00926, USA. Corresponding author: Katlyn Betway (e-mail: betwayk@mail.gvsu.edu).

${ }^{1}$ This paper is part of a Special Issue entitled: Impacts of climate change on tundra ecosystems: Three decades of results from the International Tundra Experiment (ITEX).

${ }^{*}$ Robert D. Hollister and Jeremy L. May served as Guest Editors at the time of manuscript review and acceptance; peer review and editorial decisions regarding this manuscript were handled by Anne Bjorkman and Greg Henry.

Copyright remains with the author(s) or their institution(s). This work is licensed under a Creative Attribution 4.0 International License (CC BY 4.0) http://creativecommons.org/licenses/by/4.0/deed.en_GB, which permits unrestricted use, distribution, and reproduction in any medium, provided the original author(s) and source are credited.
} 
significative en matière de traits lorsqu'ils ont été analysés individuellement. L'étude des moyennes pondérées par la communauté (MPCs) pour chaque trait n'a révélé aucun changement significatif dans le temps pour aucun trait dans aucune région. Par ailleurs, les valeurs écosystémiques estimées pour plusieurs traits importants pour le fonctionnement de l'écosystème ont montré des augmentations constantes dans le temps dans deux régions (Utqiagivik et Atqasuk). Les résultats indiquent donc que la composition et la fonction de la communauté des plantes vasculaires sont restées constantes au fil du temps ; toutefois, les augmentations documentées de la couverture végétale totale ont des implications importantes pour le fonctionnement de l'écosystème. [Traduit par la Rédaction]

Mots-clés : toundra, changement de végétation, trait fonctionnel des plantes, gradient latitudinal, moyenne pondérée par la communauté (MPC).

\section{Introduction}

The Arctic is particularly susceptible to habitat loss and degradation caused by global climate change (IPCC 2018). The tundra is among the fastest-warming biomes in the world, with mean temperatures increasing at twice the rate of the global mean (ACIA 2004; AMAP 2019). The Arctic has regularly broken historic record temperatures, experienced reduced snow cover and duration, and undergone continuous thawing of permafrost for several decades (AMAP 2019). The Arctic is therefore an indicator of future environmental change, placing it at the forefront of research on climate change impacts.

Plant communities are particularly sensitive to changes in temperature. In the Arctic, where a short growing season and low mean temperatures severely limit growth, plants are responsive to even small increases in temperature (Hollister et al. 2005; Khorsand Rosa et al. 2015; Bjorkman et al. 2020). Changes in community composition with warming have been documented across the Arctic, with increases in evergreen shrubs, deciduous shrubs, and graminoids and decreases in bryophytes and lichens being the most consistent trends across regions (Callaghan et al. 2011; Elmendorf et al. 2012; Hollister et al. 2015; Bjorkman et al. 2020). As a persistently cold and severely nutrient-limited system, the Arctic consists of plants characterized by slow growth rates and low reproductive outputs; however, studies have shown that rates for both growth and reproductive effort increase with climate warming (Hollister et al. 2005; Oberbauer et al. 2013; Mekonnen et al. 2018). Shifts in plant performance may result in shifts in ecosystem functioning. The link between performance and ecosystem function has led to an increase in studies focusing on plant functional traits as a way to study vegetation responses to changing environmental conditions (Chapin et al. 1996; Messier et al. 2010; Hudson et al. 2011; Bjorkman et al. 2018a; Myers-Smith et al. 2019).

Plant functional traits are closely linked with ecosystem functioning, specifically carbon cycling and ecosystem energy balance, which can further impact changes in climate (Lavorel and Garnier 2002; Cornelissen et al. 2007; Pearson et al. 2013). Changes in the rate of ecosystem processes such as net primary productivity and decomposition cause shifts in the net amount of carbon added to the atmosphere, affecting the overall rate of climate change. A list of traits has been generally agreed upon as having important impacts on ecosystem processes (Cornwell et al. 2008; Hudson et al. 2011). For example, plant height is positively correlated with light capture ability (Westoby et al. 2002; Mekonnen et al. 2018). Tall-statured plants have greater access to sunlight and impose shade on shortstatured plants. Additionally, leaf area is indicative of tradeoffs concerning energy and water balance (Parkhurst and Loucks 1972). Large leaves experience more water loss through transpiration, which is especially important in environments prone to desiccation. Specific leaf area (SLA), on the other hand, is positively correlated with relative growth rate and negatively correlated with leaf life span (Reich et al. 1992). Leaves with a high SLA are 
thought to be more productive, but also relatively short lived (Wilson et al. 1999). Spectral indices are also indicators of plant performance and function. Normalized difference vegetation index (NDVI) has been shown to be positively correlated with plant health and photosynthetic activity (Sellers 1985; Wang et al. 2004). Additionally, water band index (WBI) has been shown to be indicative of water stress levels in other plants (Camoglu and Genc 2013). All of these traits directly or indirectly influence ecosystem processes such as net primary productivity. Individual traits have therefore been studied in great detail, and in recent years researchers have focused on linking functional traits with community-level responses to changing environmental conditions (Soudzilovskaia et al. 2013; Baruah et al. 2017; Bjorkman et al. 2018a; Madani et al. 2018; Myers-Smith et al. 2019).

In this study, we examined nine functional traits related to plant size and leaf economics (Supplementary Table $\mathrm{S}^{2}$ ); their importance to ecosystem processes makes it critical to understand how these traits are shifting in response to community changes as the climate warms. Many studies have investigated temperature-trait relationships along environmental gradients to understand how ecosystems respond to a changing environment (Hudson et al. 2011; Muscarella and Uriarte 2016; Bjorkman et al. 2018a; Henn et al. 2018), but to our knowledge, no other studies have looked at the direct relationship between changes in species abundance and specific trait values. Additionally, looking at how shifts in community composition influence shifts in community-weighted means (CWMs) of traits may be indicative of how various arctic communities are responding to a changing climate. In this study, our aims were to (1) determine whether there is a direct relationship between shifts in species abundances and specific trait values and (2) assess whether the CWM of each trait is shifting in response to climate change over time. We hypothesize that increases or decreases in species cover over time would be associated with at least one functional trait. It is expected that increasing species have a distinct competitive advantage that will be explained by functional traits. Specifically, we expect plant height to be positively correlated with cover and leaf area to be negatively correlated with cover. Tall-statured species have greater access to sunlight and therefore a distinct advantage. Species with a large leaf area relative to species with smaller leaves are more prone to desiccation, which can be a disadvantage in Arctic communities (Savile 1972). We also hypothesize that the CWM of traits will shift over time in each region as species with optimal trait values become more abundant.

\section{Materials and methods}

\section{Study area}

The study regions were arranged along a latitudinal gradient on the North Slope of Alaska, USA (Fig. 1). Utqiagivik $\left(71^{\circ} 19^{\prime} \mathrm{N}, 156^{\circ} 36^{\prime} \mathrm{W}\right)$ is located on the north coast of Alaska along the Arctic Ocean. Utqiagivik has a mean July temperature of $\sim 4{ }^{\circ} \mathrm{C}$, and snowmelt occurs in early to mid-June. The dominant plant species are Salix spp., Carex aquatilis, and Eriophorum spp. Atqasuk, Alaska $\left(70^{\circ} 27^{\prime} \mathrm{N}, 157^{\circ} 24^{\prime} \mathrm{W}\right)$ is located $\sim 100 \mathrm{~km}$ south of Utqiagvik, has a mean July temperature of $\sim 9{ }^{\circ} \mathrm{C}$, and snowmelt occurs in late May. The dominant species are Betula nana, Salix spp., Eriophorum spp., and Carex spp. Toolik Lake, Alaska $\left(68^{\circ} 37^{\prime} \mathrm{W}, 149^{\circ} 35^{\prime} \mathrm{N}\right)$ is nestled in the foothills of the Brooks Range, has a mean July temperature of $\sim 11^{\circ} \mathrm{C}$, and snowmelt occurs in mid- to late May. The dominant plant species are Salix spp., Betula nana, and Eriophorum spp.

\footnotetext{
${ }^{2}$ Supplementary material is available with the article at https://doi.org/10.1139/as-2020-0036.
} 
Fig. 1. Location of study regions near Utqiagvik, Atqasuk, and Toolik Lake, Alaska, USA. Source: Map created using Google Earth (Google n.d.).

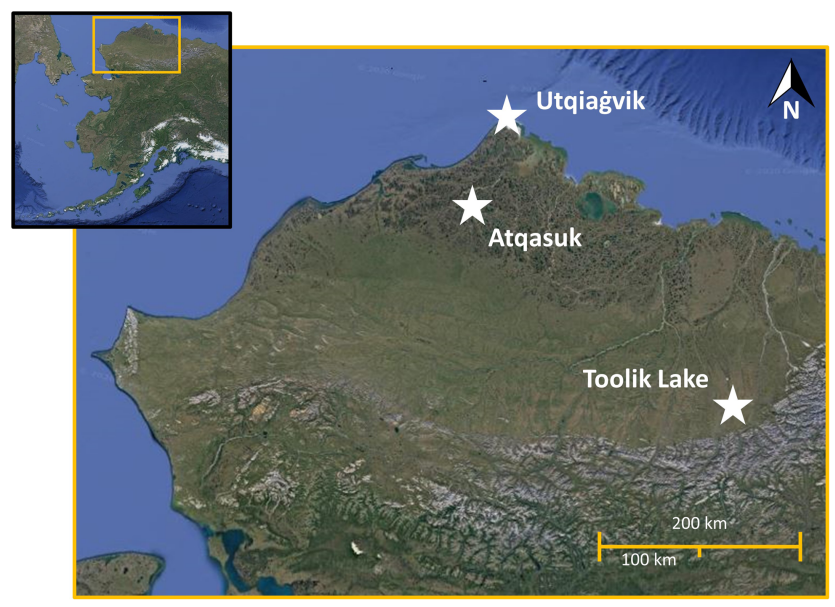

\section{Plant cover sampling}

Plant cover was measured at Utqiagvik, Atqasuk, and Toolik Lake on thirty $1 \mathrm{~m} \times 1 \mathrm{~m}$ plots spaced $100 \mathrm{~m}$ apart at each site. The sampled plots are also reported in Harris et al. (2021) and Hinkel and Nelson (2003). Plots were sampled using the nondestructive point-frame method, as outlined in the ITEX manual (Molau and Mølgaard 1996), because of its ability to detect changes in vegetation cover (May and Hollister 2012). Sampling occurred during peak growing season in 2010, 2014, and 2018 for Utqiagivik and Atqasuk and in 2008, 2014, and 2018 for Toolik Lake. A $75 \mathrm{~cm}^{2}$ grid with 100 points was leveled over each plot; three permanent markers that allowed for accurate repositioning of the grid at every sampling were lined up with the corresponding crosshairs within the grid. At each point, a ruler was lowered until first contact within the plant canopy. The height was recorded as well as the status (alive, dead) and species of the individual contacted. The same was recorded for the last species located just above the ground surface. The point-intercept method was repeated for the 100 points within the grid for the 30 plots in each of the three regions. Cover estimates exceed $100 \%$ because of vegetation layering (i.e., multiple plants being recorded at each point). Owing to difficulties with identification, all bryophytes and lichens were grouped for analysis.

\section{Plant trait collection}

All functional trait collections took place during the peak growing season in 2018. Sampling occurred within the previously established grids (Hinkel and Nelson 2003) and near other established research plots (Wahren et al. 2005; Healey et al. 2014; Hollister et al. 2015). All species names align with the accepted names within The Plant List (https:// www.theplantlist.org/(). Species were selected for functional trait analysis based on their relative abundance at a location, with special emphasis placed on species that occur at all three locations, including Carex aquatilis, Eriophorum angustifolium, Eriophorum russeolum, Eriophorum vaginatum, Luzula confusa, Pedicularis lanata, Petasites frigidus, Cassiope tetragona, Vaccinium vitis-idaea, and Salix pulchra (Table 1). Ledum palustre and Betula nana are not present at Utqiagvik, but they are dominant species at Atqasuk and Toolik Lake; including these two species creates a more representative sample for the two southern regions. Ten individuals from each species were sampled at each location (Utqiagivik, Atqasuk, and Toolik Lake). 
Table 1. Categorical abundance of the plant species measured in each study region (Utqiagivik, Atqasuk, and Toolik Lake, Alaska, USA).

\begin{tabular}{|c|c|c|c|}
\hline Species & Utqiag̀vik & Atqasuk & Toolik Lake \\
\hline $\begin{array}{l}\text { Graminoids } \\
\text { Carex aquatilis } \\
\text { Eriophorum angustifolium } \\
\text { Eriophorum russeolum } \\
\text { Eriophorum vaginatum } \\
\text { Luzula confusa }\end{array}$ & $\begin{array}{l}\text { Common } \\
\text { Common } \\
\text { Locally abundant } \\
\text { Rare } \\
\text { Locally abundant }\end{array}$ & $\begin{array}{l}\text { Common } \\
\text { Common } \\
\text { Locally abundant } \\
\text { Common } \\
\text { Locally abundant }\end{array}$ & $\begin{array}{l}\text { Common } \\
\text { Common } \\
\text { Rare } \\
\text { Common } \\
\text { Locally abundant }\end{array}$ \\
\hline $\begin{array}{l}\text { Forbs } \\
\text { Pedicularis lanata } \\
\text { Petasites frigidus }\end{array}$ & $\begin{array}{l}\text { Rare } \\
\text { Common }\end{array}$ & $\begin{array}{l}\text { Rare } \\
\text { Common }\end{array}$ & $\begin{array}{l}\text { Rare } \\
\text { Common }\end{array}$ \\
\hline $\begin{array}{l}\text { Evergreen shrubs } \\
\text { Cassiope tetragona } \\
\text { Ledum palustre } \\
\text { Vaccinium vitis-idaea }\end{array}$ & $\begin{array}{l}\text { Locally abundant } \\
\text { Not present } \\
\text { Locally abundant }\end{array}$ & $\begin{array}{l}\text { Locally abundant } \\
\text { Common } \\
\text { Common }\end{array}$ & $\begin{array}{l}\text { Common } \\
\text { Common } \\
\text { Common }\end{array}$ \\
\hline $\begin{array}{l}\text { Deciduous shrubs } \\
\text { Betula nana } \\
\text { Salix pulchra }\end{array}$ & $\begin{array}{l}\text { Not present } \\
\text { Locally abundant }\end{array}$ & $\begin{array}{l}\text { Common } \\
\text { Common }\end{array}$ & $\begin{array}{l}\text { Common } \\
\text { Common }\end{array}$ \\
\hline
\end{tabular}

Note: Species were classified as absent, rare, locally abundant, or common. Locally abundant species were found only in specific habitat types, while common species were found in most habitats.

Individuals were selected by first encounter while searching around the center of each 30-plot grid. Individuals were also sampled at least $1 \mathrm{~m}$ apart to prevent duplicate sampling of the same individual.

A series of measurements were taken for each individual in the field (measurements are outlined in Supplementary Table $S 1^{2}$ ). Plant height was measured in centimetres from the ground to the highest living vegetative structure on the plant. Leaf thickness was measured on a single healthy leaf from each individual using a dial caliper; each leaf was then placed in a coin envelope and saved for further analysis. All collected leaves consisted only of new growth from the current growing season (i.e., leaves did not contain brown tips from previous growing seasons).

In the laboratory, we took photographs of each individual leaf placed on $1 \mathrm{~cm}^{2}$ grid paper. Surface area for each leaf was calculated using ImageJ software (Schneider et al. 2012). Reflectance measurements (NDVI and WBI) were collected on a single healthy leaf of each individual using a leaf clip on a single channel Unispec-SC spectroradiometer (PP Systems, Amesbury, Massachusetts, USA). Fresh weights were taken immediately upon returning from the field (balance resolution is the nearest milligram). Next, leaf samples were placed in a drying oven at $45{ }^{\circ} \mathrm{C}$ for at least $48 \mathrm{~h}$. Dry weights were then taken using the same balance. The aforementioned traits were also used to calculate other traits such as SLA and leaf dry matter content (LDMC). A nutrient analysis to determine nitrogen content and carbon/nitrogen ratio using the combustion method was conducted at the Agroecology Lab at Florida International University. Leaf samples were combined for each species for each region to conduct a single nutrient analysis.

\section{Community-weighted means of plant traits}

The community-weighted mean (CWM) for each trait was calculated for each plot for each sampling across all three regions using the following formula:

$\mathrm{CWM}=\sum_{i=1}^{n}\left(p_{i} \times\right.$ trait $\left._{i}\right)$ 
where $p_{i}$ is the relative abundance of species $i$ in the plot, and trait ${ }_{i}$ is the mean trait value of species $i$ (Duarte et al. 2018). Relative abundance for our 12 focal species was calculated for each sampling by dividing the number of contacts for each species by the total number of alive vascular contacts (bryophytes, lichens, litter, and standing dead were excluded from relative cover calculations). Mean trait values for our 12 focal species were obtained during a single sampling in 2018. For species not included in our trait sampling, we obtained individual mean trait values from the Tundra Trait Team (TTT) database (Bjorkman et al. 2018b). Trait data did not exist for all missing species, however, and included only some of our measured traits. A summary of the additional species included in the CWM trait analysis from the TTT database is outlined in Supplementary Table $\mathrm{S2}^{2}$. No additional data were available for WBI, NDVI, or leaf thickness. The percent cover occupied by the included species was calculated by dividing the sum of the absolute cover for the included species by the total alive vascular cover for each sampling. We also calculated estimated ecosystem values for a subset of traits that are considered important for ecosystem functioning using absolute cover rather than relative cover.

\section{Statistical analyses}

Means and standard errors were calculated for each functional trait and species (Supplementary Table $\mathrm{S}^{2}$ ). All statistical analyses were performed using R statistical software version 3.6.2 ( $\mathrm{R}$ Core Team 2018). Individuals that had multiple trait values more than 2.2 standard deviations away from the trait mean were identified as outliers and removed (about one to two individuals per species). Using 2.2 standard deviations allowed us to identify outliers while preserving the natural amount of intraspecific variation within the sampled population. Because individuals that were removed had multiple outliers (several traits for a single individual), we assumed they were either unhealthy individuals or that errors were made during measurements. Whole individuals rather than individual trait values were removed to preserve a data matrix without missing values. All variables were tested for normality using the Shapiro-Wilk test. Plant height, leaf area, leaf thickness, and LDMC were log transformed to fulfill normality requirements. To identify change over time, repeated-measures analysis of variance (ANOVA) using the package MASS in $R$ (Venables and Ripley 2002) was performed for each region (with plots as the replicates; $n=30$ ) for the cover of a plant species or growth form, and the CWM or the estimated ecosystem value of a trait. $P$ values were adjusted for multiple comparisons using the Benjamini-Hochberg procedure.

To assess whether certain traits are associated with changes in cover, canonical correspondence analysis (CCA) was conducted using the package vegan in R (Oksanen et al. 2019), using mean cover values for each species for each sampling in relation to the mean trait values for each species. For the CCA, we took the mean percent cover for each species at each sampling across all 30 sampled plots for the three regions; we also took the mean trait value of all 10 collected individuals at each region. Because the samples used to generate the CCA were not independent, our model cannot be directly applied to areas outside of our study sites. However, CCA is much more flexible than regression models, and we believe the results can provide a baseline for future studies investigating relationships between functional traits and cover. CCA maximizes correlation between plant community composition and trait variables, revealing underlying trends in the data. Pearson and Spearman rank correlations between mean trait values for each species and change in mean cover values of that species from first (2010 for Utqiagivik and Atqasuk, 2008 for Toolik Lake) to last (2018) sampling were performed for each region and across all regions to test individual relationships within the CCA. $P$ values for correlations were adjusted for multiple comparisons using the Benjamini-Hochberg procedure. 
Fig. 2. Mean plant cover at Utqiagvik, Atqasuk, and Toolik Lake, Alaska, USA, sampled between 2008 and 2018. Cover was measured using the nondestructive point-frame method. The species that were measured for plant traits are denoted; other plants are grouped by growth form.

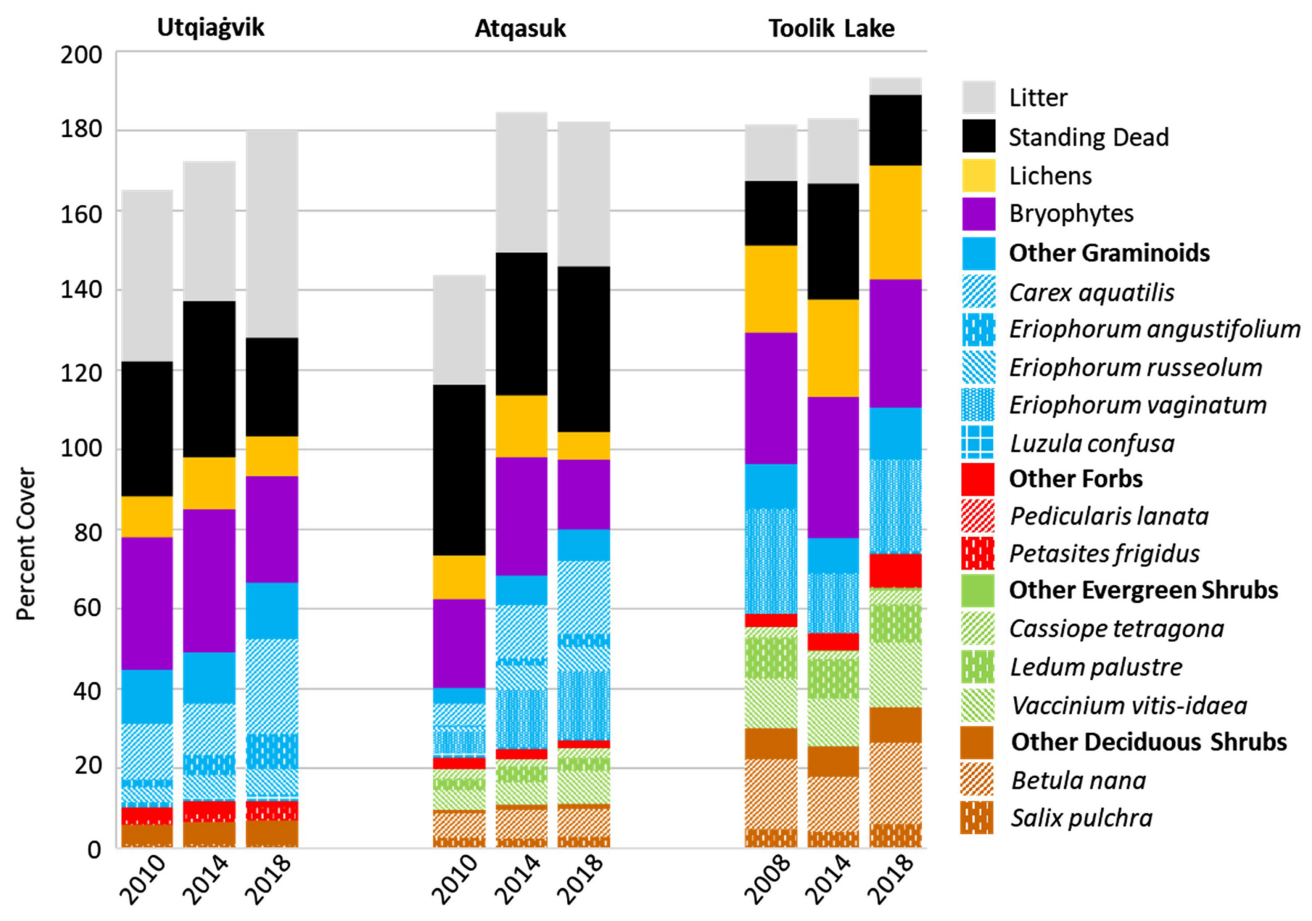

\section{Results}

Results from repeated-measures ANOVA showed that only one species significantly increased in cover in only one region (Fig 2; Supplementary Table $S 4^{2}$ ) - Carex aquatilis $(P=0.02, F=10.42)$ increased at Atqasuk. No single species significantly increased or decreased in cover at Utqiagvik or Toolik Lake. When analyzed by growth form, however, we found additional significant results: graminoids increased at Utqiagivik $(P<0.01$, $F=18.51)$ and Atqasuk $(P<0.01, F=57.32)$, and forbs increased at Toolik Lake $(P=0.02$, $F=10.11)$. Litter also decreased at Toolik Lake $(P=0.01,13.84)$. Growth-form analyses included all species found within each region rather than just our 12 focal species.

CCA suggested patterns between change in cover and trait values (Fig. 3). Species that showed a significant increase in cover were associated with high leaf nitrogen content, and species with a decrease in cover (though nonsignificant) were associated with high LDMC. Carbon/nitrogen ratio was eliminated from the ordination owing to variance inflation with leaf nitrogen content. Once carbon/nitrogen ratio was removed, all variance inflation factors were less than four. The proportion of constrained variance explained was $48.2 \%$. Post hoc permutation testing using the anova.cca function in $\mathrm{R}$ revealed that the model $(P=0.02)$ and first axis $(P=0.02)$ were significant. No Pearson or Spearman rank correlations between change in cover and each individual trait were significant.

None of the CWMs for any of the seven traits significantly increased or decreased over time in any region (Fig. 4; Supplementary Table $S 5^{2}$ ). The relative cover of all species included in the combined CWM trait analysis are shown in Fig. 4 as percentages above the corresponding site and sampling. Estimated ecosystem values for every trait increased over 
Fig. 3. Canonical correspondence analysis of mean cover values from each year of sampling and mean trait values for 12 Arctic plant species (species codes follow the pattern of genus (GEN) + species (SPE) = GENSPE in each region (represented by different symbols for Utqiagivik, Atqasuk, and Toolik Lake). Traits are defined as follows: VegHt, plant height $(\mathrm{cm})$; LeafArea, leaf area $\left(\mathrm{cm}^{2}\right)$; SLA, specific leaf area $\left(\mathrm{cm}^{2} / \mathrm{g}\right)$; WBI, water band index; NDVI, normalized difference vegetation index; LeafThick, leaf thickness $(\mathrm{mm})$; LDMC, leaf dry matter content $(\mathrm{g} / \mathrm{g})$; and LeafN, leaf nitrogen content. The proportion of constrained variation explained was $61.7 \%$. Results from post hoc analysis $(999$ permutations) indicate that the model $(P<0.01)$ and first axis $(P<0.01)$ are significant. To visualize how the cover of each species changed from the first to the last sampling, the species code is represented in blue for increasing cover and orange for decreasing cover, with darker shades showing the most change and lighter shades showing the least. Species that significantly increased (repeated-measures ANOVA; $P<0.05$ ) are indicated with an asterisk.

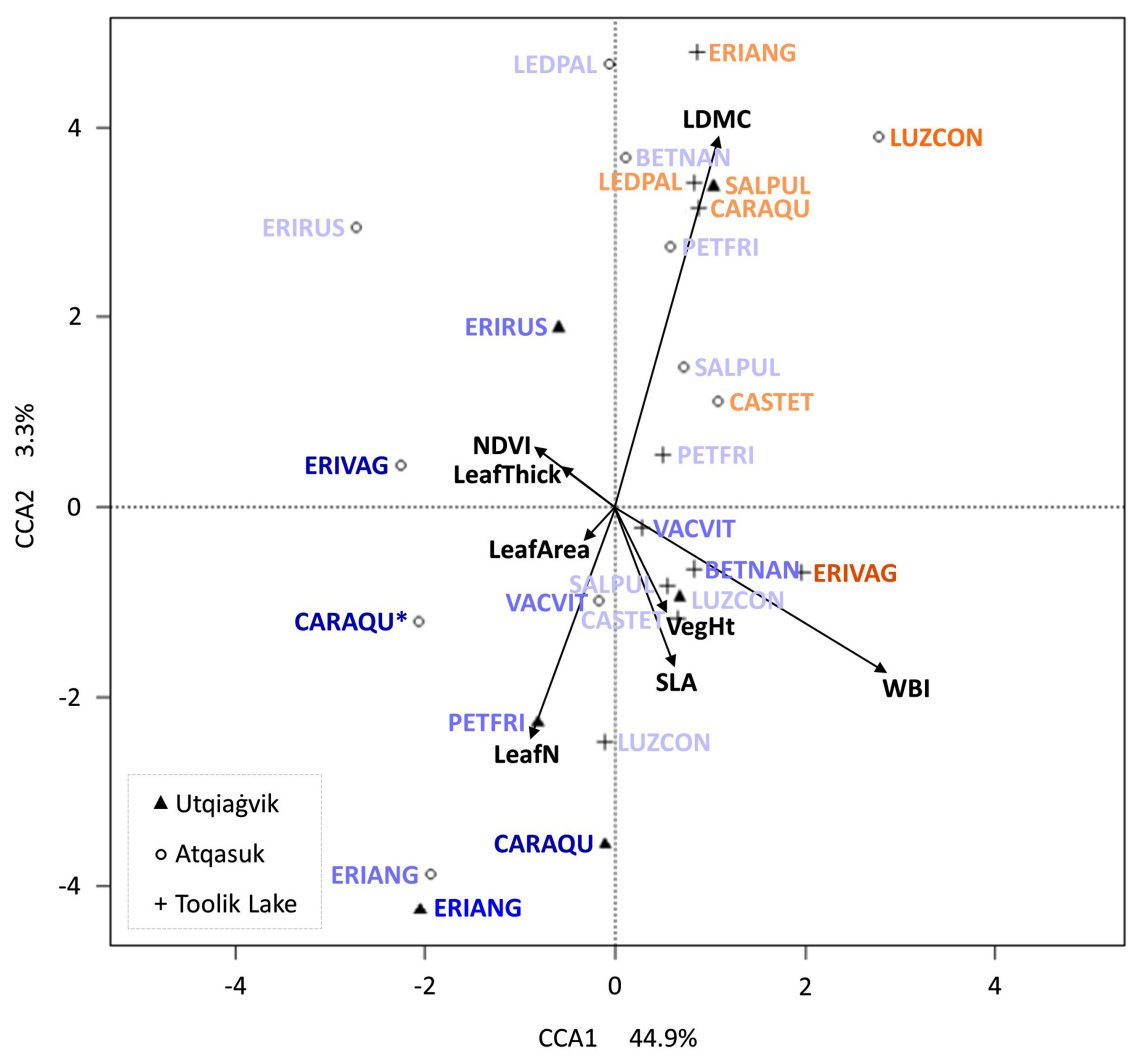

time at Utqiagvik and Atqasuk (Fig. 5; Supplementary Table S6²); no estimated ecosystem values significantly changed at Toolik Lake.

\section{Discussion}

\section{Change in cover}

Our study regions span a latitudinal gradient that is coupled with a temperature gradient: the northernmost region had the lowest mean summer temperature, and the southernmost region had the warmest mean summer temperature. Distinct differences in community composition among our study regions reflect this temperature gradient. Utqiagivik was dominated mainly by graminoid species (specifically Carex aquatilis and Eriophorum spp.) (Fig. 2). Atqasuk was also dominated by graminoids, but with much larger evergreen and deciduous shrub cover. Toolik Lake had a more even distribution of graminoids, evergreen shrubs, and deciduous shrubs and also greater total vascular cover than 
Fig. 4. Contributions of species to community-weighted means (CWMs) for nine different functional traits. CWM traits were calculated for three samplings between 2008 and 2018 at Utqiagivik, Atqasuk, and Toolik Lake, Alaska, USA. Cover data were collected at each sampling, and trait data were collected in 2018. CWM traits were calculated by multiplying the trait mean by the mean relative cover of each species for each sampling for each region. When possible, trait values for species not measured were obtained from the Tundra Trait Team (TTT) database (Bjorkman et al. 2018b); the resulting percent relative cover that the included species represent is displayed above each sampling year. No additional species from the TTT database were included in calculations for WBI, NDVI, and leaf thickness. Traits are defined as follows: VegHt, plant height $(\mathrm{cm})$; LeafArea, leaf area $\left(\mathrm{cm}^{2}\right)$; SLA, specific leaf area $\left(\mathrm{cm}^{2} / \mathrm{g}\right)$; WBI, water band index; NDVI, normalized difference vegetation index; LeafThick, leaf thickness (mm); LDMC, leaf dry matter content (g/g); LeafN, leaf nitrogen content; $\mathrm{C} / \mathrm{N}$ ratio, carbon/nitrogen ratio.
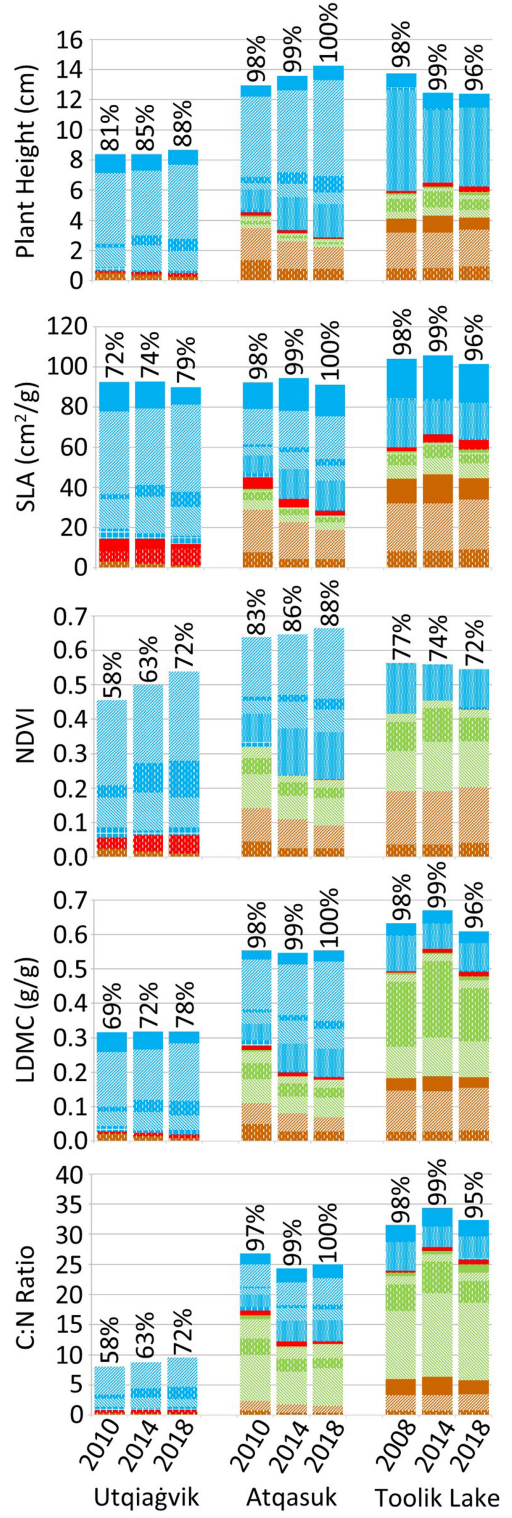
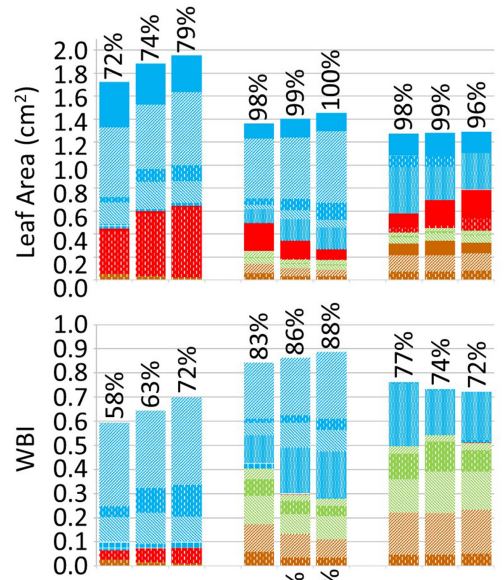

ळे ڤ̊
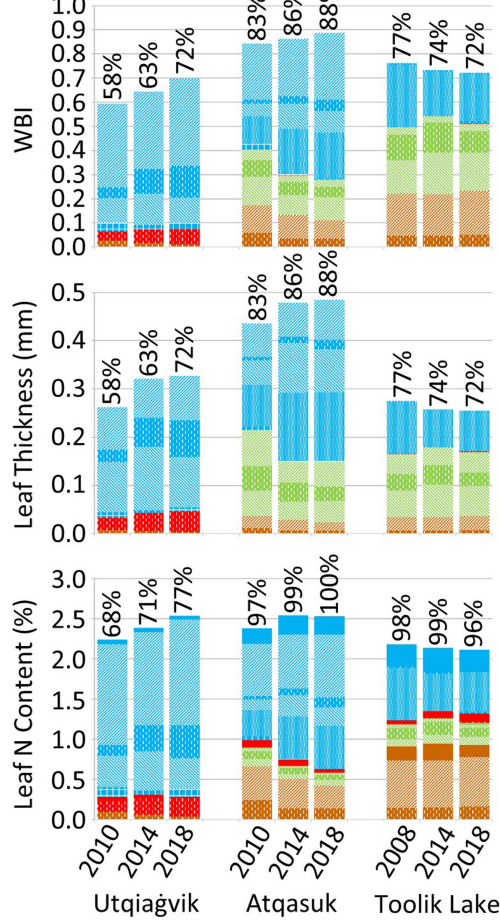

Other Graminoids

Carex aquatilis

i. Eriophorum angustifolium

Eriophorum russeolum

Eriophorum vaginatum

III Luzula confusa

Other Forbs

W. Pedicularis lanata

Petasites frigidus

Other Evergreen Shrubs

Cassiope tetragona

Ledum palustre

Vaccinium vitis-idaea

Other Deciduous Shrubs

Betula nana

诖 Salix pulchra 
Fig. 5. Estimated ecosystem values of a subset of functional traits that are considered important to ecosystem functioning. Values were calculated using absolute cover for three samplings between 2008 and 2018 at Utqiagvik, Atqasuk, and Toolik Lake, Alaska, USA, for the same species included in the community-weighted mean (CWM) trait analysis. Traits that significantly changed over time are indicated with a red asterisk (*) based on repeated-measures ANOVA $(P<0.05)$.
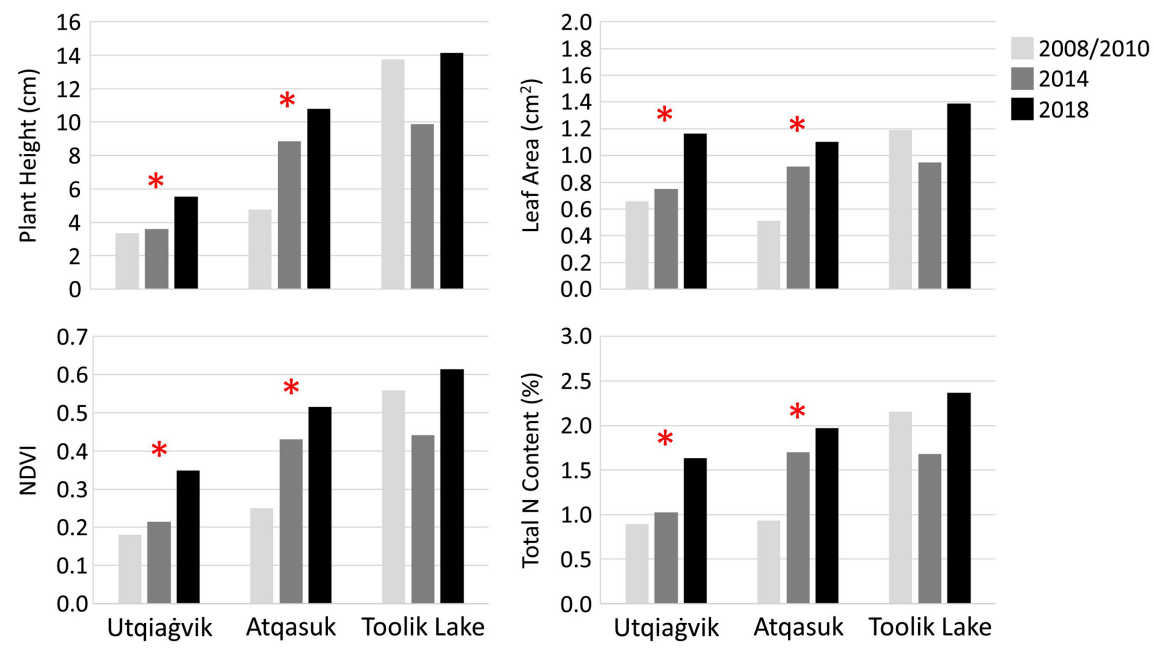

the two northern regions. Toolik Lake also had a greater number of species that were not included in our trait sampling, indicating greater species richness. Our study regions capture three unique communities that are common throughout the Arctic region, thus providing a baseline for future studies looking at the relationship between functional traits and cover change within similar Arctic communities.

Changes in species-level abundances in response to a changing climate over time are consistent with more generalized trends focused on growth forms (Callaghan et al. 2011; Elmendorf et al. 2012; Hollister et al. 2015; Bjorkman et al. 2020). Graminoids are increasing in the two northern regions (Utqiagivik and Atqasuk). Not all species within each growth form are increasing in the same way, however. Within graminoids, Carex aquatilis significantly increased in cover over time in only one region, but E. angustifolium, E. russeolum, E. vaginatum, and Luzula confusa showed no change. The sedge Carex aquatilis is a widespread, common, and dominant species that occurs across multiple habitats as opposed to a rare (e.g., Pedicularis lanata) or locally abundant species that only occurs within specific habitat types (e.g., E. russeolum, Luzula confusa, Cassiope tetragona), which may explain why it showed significant changes in cover. Species-level responses in our analyses are limited in that not all species present in each region occurred in at least one of the sampled plots (e.g., Pedicularis lanata is present in all three regions, but was not sampled in any plot). More rare species are therefore excluded from some analyses, limiting our focus primarily to common species. Owing to the extremely small proportion of the landscape taken up by rare species compared with the overwhelming proportion represented by more common species (e.g., E. vaginatum in the two southern regions; Fig. 2), we focused on the common species because shifts in abundances will have a much greater impact on overall ecosystem functioning.

Shifts in community composition were more pronounced at Utqiagivik and Atqasuk, and species-level responses were more dynamic. Only one species in one region increased in cover over time (Carex aquatilis; Supplementary Table S4${ }^{2}$ ), but many species experienced small fluctuations in cover between samplings. Because our analyses included only three 
samplings over 8-10 years, a trend that would emerge from more consistent sampling may have been obscured, preventing the detection of more subtle responses. Therefore, our results are likely driven by the few species with large changes in cover between samplings.

Graminoid species, particularly Carex aquatilis, are driving change in cover at Utqiagvik and Atqasuk. Sedge species such as Carex aquatilis retain their old growth (i.e., their green leaves from previous years) in combination with new growth each growing season. Other species, including most forbs and some grasses, are herbaceous perennials that regrow their leaves each year. Still others (e.g., evergreen shrubs) retain their growth over several years, resulting in slow relative growth rates (Reich et al. 1992; Mekonnen et al. 2018). Research has shown that graminoids accumulate biomass quicker than other growth forms in response to reduced resource limitation (Chapin and Shaver 1989). Greater biomass accumulation may partially be the result of differences in growth strategies (e.g., leaf retention in some sedge species), enabling species to populate bare landscapes more quickly. Graminoids' growth strategy coupled with possible increases in nutrient availability in the Arctic (Nadelhoffer et al. 1992; Schimel et al. 2004) may explain their large increases in cover in the northern regions. Previous research has shown that shrubs also increase in cover in response to warming (Elmendorf et al. 2012; Hollister et al. 2015). Because shrubs have a slower relative growth rate compared with graminoids, however, it is possible that three samplings were not enough to detect changes in shrub cover over time. An increase in graminoids is absent at Toolik Lake because the landscape is already densely populated, with few bare patches available for colonization (total vascular cover reaches only $66.5 \%$ at Utqiagvik, but exceeds $100 \%$ at Toolik Lake; Fig. 2). Therefore, it is possible that combinations of traits that are linked with the ability to retain leaves for multiple growing seasons are most closely associated with change in cover.

\section{Functional traits and change in cover}

CCA suggests significant increases in cover are associated with high leaf nitrogen content, particularly at Utqiagivik and Atqasuk (Fig. 3). We therefore expect that species with high leaf nitrogen content such as Carex aquatilis and E. angustifolium will either continue to increase in cover or remain dominant. Because the Arctic is such a severely nutrientlimited system, it is important that plants have the ability to efficiently uptake nutrients from the soil. Leaf nitrogen concentrations are therefore indicative of resource availability and are closely correlated with growth and photosynthetic rates (Evans 1989; Hudson et al. 2011). It is also important that Arctic plants have the ability to photosynthesize at low temperatures while maximizing carbon fixation due to constraints set by a short growing season (Caldwell et al. 1978). Previous research has suggested that cold-tolerant species are more plastic in regard to photosynthetic temperature acclimation than cold-sensitive species (Yamori et al. 2010). Species that already have a high photosynthetic capacity (and are therefore more cold tolerant) may respond more readily to warmer temperatures and a longer growing season. As these species increase in cover over time, the overall functionality of the ecosystem will shift as well, causing productivity and net carbon exchange to increase over time with rising temperatures (Reich et al. 1999; Mekonnen et al. 2018). Increases in net primary productivity are linked to a deepening of the active layer, increased microbial decomposition, and therefore greater nutrient availability (Mekonnen et al. 2018), providing a more nutrient-rich environment for Arctic herbivores. Increases in the biomass of common food sources for herbivores coupled with a higher nutrient content in leaves would be able to support larger herbivore populations and potentially increase the overall biodiversity in the Arctic (Barrio et al. 2016).

CCA also suggests that decreases in cover are associated with high LDMC (Fig. 3). We therefore expect that species with a high LDMC such as Ledum palustre to be outcompeted 
and to decrease in cover over time. Prior research has demonstrated a correlation between LDMC and relative growth rate, with higher LDMC correlating with slower growth (Gross et al. 2007). It is possible that as environmental conditions become more favorable in the Arctic, slow-growing species are being outcompeted by fast-growing species such as graminoids. More research on the relationship between LDMC and growth strategies of tundra species may further explain why species with a high LDMC are decreasing in cover over time.

Though leaf nitrogen content and LDMC seem to be related to change in species cover, our results from the Pearson and Spearman rank correlations do not support these relationships. It is possible that future analyses focusing on individual regions and all species that occur within them rather than all regions combined with only the dominant species may have revealed underlying intraregional trends. The fact that no correlations were significant also emphasizes the need to focus on multiple traits in combination with each other rather than an examination of individual traits. Further analyses incorporating multivariate approaches (i.e., ordinations) are likely to better identify relationships between functional traits and other aspects of community dynamics (such as change in plant cover) and ecosystem functioning.

\section{Community-weighted means and change in cover}

Because species-level responses are so dynamic, many studies have investigated shifts in CWM traits (Kichenin et al. 2013; Muscarella and Uriarte 2016; Bjorkman et al. 2018a). A CWM considers the relative abundance of species in addition to species-specific responses. More dominant species therefore have a greater effect on the overall community trait value than rare species. However, because our CWM trait values were calculated based on a single trait sampling (2018) and several cover samplings (2008/2010, 2014, 2018), only relative cover was contributing to shifts in CWM traits over time. Our results do not consider shifts in trait values over time, but several studies show that many traits are slow to respond to changing environmental conditions, if they change at all (Hudson et al. 2011; Kichenin et al. 2013; Bjorkman et al. 2018a). For example, Hudson et al. (2011) showed that leaf chemistry traits (e.g., leaf nitrogen concentration) were not affected by long-term warming; growth traits (e.g., leaf size and SLA) were more sensitive to warming, but responses varied among species. In general, our species showed an increase in leaf size and plant height and a decrease in SLA. It is likely that over the decade of cover sampling, our study species experienced some shifts in size- and growth-related functional traits; however, our study investigated differences in traits between species (e.g., tall- versus short-statured plants) and their relationship with cover change. Therefore, we believe our results still have important implications with regard to shifts in ecosystem functioning in a changing environment.

Our results indicate that none of the three study regions (Utqiagivik, Atqasuk, Toolik Lake) had experienced significant changes in the CWM of traits over time (Fig. 4; Supplementary Table $\mathrm{S}^{2}$ ). A lack of significant changes in CWM trait values over time indicates that the vascular community composition has remained functionally consistent. However, the estimated ecosystem values for traits show consistent increases at the two northern regions due to increasing plant cover (Fig. 5; Supplementary Table $S 6^{2}$ ). Continued increases in plant cover will likely have important implications for ecosystem functioning. For example, increased estimated total nitrogen content at Utqiagvik and Atqasuk (Fig. 5) indicates a change in resource availability and therefore photosynthesis (Evans 1989) over time, and increased estimated NDVI indicates increases in primary productivity (Sellers 1985). Leaf area is directly correlated with plant biomass (Goswami et al. 2015), and both northernmost Utqiagivik and southernmost Atqasuk showed significant 
estimated increases in both. Finally, increased estimated plant height over time increases the ability of plants to capture light (Westoby et al. 2002) and could decrease surface albedo in the winter months, influencing the rate and timing of spring snowmelt (Foley 2005).

Approaches such as CWMs that use species-specific trait values are important to account for high levels of interspecific variation. There is a large amount of variation among species even within the same growth form, resulting in overgeneralizations with regard to effects on ecosystem functioning (Saccone et al. 2017; Thomas et al. 2019). There is also large variation in traits at the population level within a species. For example, the SLA of E. angustifolium at Toolik Lake is more than twice the SLA of E. angustifolium at Utqiagivik and Atqasuk. Such large amounts of intraspecific variation could be attributed to levels of phenotypic plasticity and (or) local adaptation. Phenotypic plasticity can be very advantageous for plants because it enables them to respond to changes to their environment (Sultan 2000), though there is evidence that the level of plasticity can be restricted under abiotic extremes and the presence of herbivory (Valladeras et al. 2007). Other research has shown that shading can cause plants to increase their SLA by $55.4 \%$ on average (Liu et al. 2016), which may explain the large increase in SLA in the Toolik Lake populations. Expansion of erect shrubs in the low Arctic as a result of climate warming, including at Toolik Lake (Myers-Smith and Hik 2017), imposes shading on more low-statured plants. Shading can also cause plants to suffer from decreased productivity and nutrient uptake as a result of reduced solar radiation (Mekonnen et al. 2018). Plants that are unable to cope with shading from tall-statured shrubs therefore decrease in cover as they are outcompeted over time. While it is likely that phenotypic plasticity plays a role in such stark differences in traits between populations, the level of plasticity and rate of adaptation cannot be determined without further experimentation (i.e., common garden or reciprocal transplant experiments). Therefore, it is also important to look at region-specific responses with regard to shifting community composition.

Shifts in CWM traits have been related to environmental gradients under the hypothesis that species converge on a locally optimal phenotype and that species abundance is related to proximity to an optimal trait value (Laughlin et al. 2012; Muscarella and Uriarte 2016; Henn et al. 2018). Convergence toward an optimal phenotype seems to occur in resourcelimited ecosystems driven by facilitation of species (e.g., the Arctic) rather than in resource-abundant ecosystems driven by competition (Henn et al. 2018). Owing to the nature of tradeoffs within the plant economic spectrum (Díaz et al. 2016), however, it seems that investigating traits in multidimensional trait space is important to consider in future analyses. Multiple traits may interact to determine niche differentiation between species, indicating tradeoffs in plant performance and function (Diaz et al. 2004; McGill et al. 2006; Kraft et al. 2015; Díaz et al. 2016). A multidimensional approach to trait-based studies may therefore be more indicative of cover-trait relationships and give us a better understanding of how future shifts in trait values will influence ecosystem functioning.

\section{Future directions}

In order to capture a more comprehensive view of how plant communities in the tundra are responding to a changing climate, functional trait data must be collected for all species across multiple regions. The TTT database includes tens of thousands of measurements for 18 plant traits collected from multiple regions throughout the Arctic (Bjorkman et al. 2018b); however, there are gaps for many regions and (or) species. Filling in data gaps and extending the trait list will facilitate countless studies investigating functional trait trends.

Additionally, collecting trait measurements over a long period of time will indicate whether trait values are changing or remaining constant. It is likely that traits are shifting as environmental conditions change, but data regarding shifts in traits are limited to very 
few studies. Because different regions are experiencing different environmental changes, it is important to conduct trait-based studies on broader geographic scales.

\section{Acknowledgements}

We thank Matthew Simon and Melissa Lau for assistance with trait data collection and prior members of the Arctic Ecology Program at Grand Valley State University for inspiration and for conducting vegetation cover measurements at Utqiagivik and Atqasuk. We also thank all researchers and field technicians who assisted with vegetation sampling at Toolik Lake. We thank CH2MHill Polar Services and UIC Science for logistical support at Utqiagvik and Atqasuk, and staff at the University of Alaska's Institute of Arctic Biology and CH2MHill Polar Services for support at Toolik Field Station.

\section{Funding statement}

This work was funded by National Science Foundation grants PLR-1504381 and PLR-1836898.

\section{Data availability statement}

Cover data are available at the NSF Arctic Data Center (https://arcticdata.io/). Functional trait data was submitted to the TTT and will be included in version 2 of the database. Functional trait data is also publicly available on Figshare (https://doi.org/10.6084/ m9.figshare.14511987.v1). All data is also available upon request from the corresponding author.

\section{References}

ACIA. 2004. Impacts of a warming Arctic-Arctic climate impact assessment. Cambridge University Press, Cambridge, UK. December 2004. 144. ISBN 0521617782.

AMAP. 2019. AMAP climate change update 2019: an update to key findings of snow, water, ice and permafrost in the Arctic (SWIPA) 2017. Arctic Monitoring and Assessment Program (AMAP). Oslo, Norway. p. 12.

Barrio, I.C., Bueno, C.G., Gartzia, M., Soininen, E.M., Christie, K.S., Speed, J.D., et al. 2016. Biotic interactions mediate patterns of herbivore diversity in the Arctic. Glob. Ecol. Biogeogr. 25: 1108-1118. doi: 10.1111/geb.12470.

Baruah, G., Molau, U., Bai, Y., and Alatalo, J.M. 2017. Community and species-specific responses of plant traits to 23 years of experimental warming across subarctic tundra plant communities. Sci. Rep. 7: 1-11. doi: 10.1038/ s41598-017-02595-2.

Bjorkman, A.D., Myers-Smith, I.H., Elmendorf, S.C., Normand, S., Rüger, N., Beck, P.S., et al. 2018a. Plant functional trait change across a warming tundra biome. Nature, 562: 57-62. doi: 10.1038/s41586-018-0563-7.

Bjorkman, A.D., Myers-Smith, I.H., Elmendorf, S.C., Normand, S., Thomas, H.J., Alatalo, J.M., et al. 2018b. Tundra Trait Team: A database of plant traits spanning the tundra biome. Glob. Ecol. Biogeogr. 27: 1402-1411. doi: 10.1111/geb.12821.

Bjorkman, A.D., Criado, M.G., Myers-Smith, I.H., Ravolainen, V., Jónsdóttir, I.S., Westergaard, K.B., et al. 2020. Status and trends in Arctic vegetation: Evidence from experimental warming and long-term monitoring. Ambio, 49: 678-692. doi: 10.1007/s13280-019-01161-6. PMID: 30929249.

Caldwell, M.M., Johnson, D.A., and Fareed, M. 1978. Constraints on Tundra Productivity: Photosynthetic Capacity in Relation to Solar Radiation Utilization and Water Stress in Arctic and Alpine Tundras. In Vegetation and Production Ecology of an Alaskan Arctic Tundra. Ecological Studies (Analysis and Synthesis), Vol. 29. Edited by L.L. Tieszen Springer, New York, N.Y. pp. 323-342. doi: 10.1007/978-1-4612-6307-4_13.

Callaghan, T.V., Tweedie, C.E., Åkerman, J., Andrews, C., Bergstedt, J., Butler, M.G., et al. 2011. Multi-decadal changes in tundra environments and ecosystems: synthesis of the International Polar Year-Back to the Future Project (IPY-BTF). Ambio, 40: 705. doi: 10.1007/s13280-011-0179-8. PMID: 21954732.

Camoglu, G., and Genc, L. 2013. Determination of water stress using thermal and spectral indices from green bean canopy. Fresenius Environ. Bull. 22: 3078-3088.

Chapin, F.S., III, and Shaver, G.R. 1989. Differences in growth and nutrient use among arctic plant growth forms. Funct. Ecol. 3: 73-80. doi: 10.2307/2389677.

Chapin, F.S., III, Bret-Harte, M.S., Hobbie, S.E., and Zhong, H. 1996. Plant functional types as predictors of transient responses of arctic vegetation to global change. J. Veg. Sci. 7: 347-358. doi: 10.2307/3236278.

Cornelissen, J.H., Van Bodegom, P.M., Aerts, R., Callaghan, T.V., Van Logtestijn, R.S., Alatalo, J., et al. 2007. Global negative vegetation feedback to climate warming responses of leaf litter decomposition rates in cold biomes. Ecol. Lett. 10: 619-627. doi: 10.1111/j.1461-0248.2007.01051.x. PMID: 17542940. 
Cornwell, W.K., Cornelissen, J.H., Amatangelo, K., Dorrepaal, E., Eviner, V.T., Godoy, O., et al. 2008. Plant species traits are the predominant control on litter decomposition rates within biomes worldwide. Ecol. Lett. 11: 1065-1071. doi: 10.1111/j.1461-0248.2008.01219.x. PMID: 18627410.

Diaz, S., Hodgson, J.G., Thompson, K., Cabido, M., Cornelissen, J.H., Jalili, A., et al. 2004. The plant traits that drive ecosystems: evidence from three continents. J. Veg. Sci. 15: 295-304. doi: 10.1111/j.1654-1103.2004.tb02266.x.

Díaz, S., Kattge, J., Cornelissen, J.H., Wright, I.J., Lavorel, S., Dray, S., et al. 2016. The global spectrum of plant form and function. Nature, 529: 167-171. doi: 10.1038/nature16489. PMID: 26700811.

Duarte, L.D., Debastiani, V.J., Carlucci, M.B., and Diniz-Filho, J.A.F. 2018. Analyzing community-weighted trait means across environmental gradients: should phylogeny stay or should it go? Ecology, 99: 385-398. doi: 10.1002/ecy.2081. PMID: 29121389.

Elmendorf, S.C., Henry, G.H., Hollister, R.D., Björk, R.G., Bjorkman, A.D., Callaghan, T.V., et al. 2012. Global assessment of experimental climate warming on tundra vegetation: heterogeneity over space and time. Ecol. Lett. 15: 164-175. doi: 10.1111/j.1461-0248.2011.01716.x. PMID: 22136670.

Evans, J.R. 1989. Photosynthesis and nitrogen relationships in leaves of $C_{3}$ plants. Oecologia, 78: 9-19. doi: 10.1007/ BF00377192. PMID: 28311896.

Foley, J.A. 2005. Tipping points in the tundra. Science, 310(5748): 627-628. doi: 10.1126/science.1120104. PMID: 16254174.

Google. n.d. [Google map of study regions Utqiagvik, Atqasuk, and Toolik Lake Alaska, USA]. Available from https:// earth.google.com/web/@66.79822644,-146.49841174,418.0499937a,2052890.56105435d,35y,360h,0t,0r. [accessed 18 November 2020].

Goswami, S., Gamon, J., Vargas, S., and Tweedie, C. 2015. Relationships of NDVI, Biomass, and Leaf Area Index (LAI) for six key plant species in Barrow, Alaska. PeerJ PrePrints. 3: e913v1. doi: 10.7287/peerj.preprints.913v1.

Gross, N., Suding, K.N., and Lavorel, S. 2007. Leaf dry matter content and lateral spread predict response to land use change for six subalpine grassland species. J. Veg. Sci. 18: 289-300. doi: 10.1111/j.1654-1103.2007.tb02540.x.

Harris, J.A., Hollister, R.D., Botting, T.F., Tweedie, C.E., Betway, K.R., May, J.L., et al. 2021. Understanding the climate impacts on decadal vegetation change in northern Alaska. Arct. Sci. 8(1) This issue. doi: 10.1139/AS-2020-0050.

Healey, N.C., Oberbauer, S.F., Ahrends, H.E., Dierick, D., Welker, J.M., Leffler, A.J., et al. 2014. A mobile instrumented sensor platform for long-term terrestrial ecosystem analysis: an example application in an arctic tundra ecosystem. J. Environ. Inform. 24: 1-10. doi: 10.3808/jei.201400278.

Henn, J.J., Buzzard, V., Enquist, B.J., Halbritter, A.H., Klanderud, K., Maitner, B.S., et al. 2018. Intraspecific trait variation and phenotypic plasticity mediate alpine plant species response to climate change. Front. Plant Sci. 9: 1548. doi: 10.3389/fpls.2018.01548. PMID: 30483276.

Hinkel, K.M., and Nelson, F.E. 2003. Spatial and temporal patterns of active layer thickness at Circumpolar Active Layer Monitoring (CALM) sites in northern Alaska, 1995-2000. J. Geophys. Res. 108: 9-1-9-13. doi: 10.1029/ 2001JD000927.

Hollister, R.D., Webber, P.J., and Bay, C. 2005. Plant response to temperature in northern Alaska: implications for predicting vegetation change. Ecology, 86: 1562-1570. doi: 10.1890/04-0520.

Hollister, R.D., May, J.L., Kremers, K.S., Tweedie, C.E., Oberbauer, S.F., Liebig, J.A., et al. 2015. Warming experiments elucidate the drivers of observed directional changes in tundra vegetation. Ecol. Evol. 5: 1881-1895. doi: 10.1002/ ece3.1499. PMID: 26140204.

Hudson, J.M.G., Henry, G.H.R., and Cornwell, W.K. 2011. Taller and larger: shifts in Arctic tundra leaf traits after 16 years of experimental warming. Glob. Chang. Biol. 17: 1013-1021. doi: 10.1111/j.1365-2486.2010.02294.x.

IPCC. 2018. Global warming of $1.5^{\circ} \mathrm{C}$ : An IPCC special report on the impacts of global warming of $1.5^{\circ} \mathrm{C}$ above pre-industrial levels and related global greenhouse gas emission pathways, in the context of strengthening the global response to the threat of climate change, sustainable development, and efforts to eradicate poverty. Intergovernmental Panel on Climate Change.

Khorsand Rosa, R., Oberbauer, S.F., Starr, G., Parker La Puma, I., Pop, E., Ahlquist, L., and Baldwin, T. 2015. Plant phenological responses to a long-term experimental extension of growing season and soil warming in the tussock tundra of Alaska. Glob. Chang. Biol. 21: 4520-4532. doi: 10.1111/gcb.13040. PMID: 26183112.

Kichenin, E., Wardle, D.A., Peltzer, D.A., Morse, C.W., and Freschet, G.T. 2013. Contrasting effects of plant inter- and intraspecific variation on community-level trait measures along an environmental gradient. Funct. Ecol. 27: 1254-1261. doi: 10.1111/1365-2435.12116.

Kraft, N.J., Godoy, O., and Levine, J.M. 2015. Plant functional traits and the multidimensional nature of species coexistence. Proc. Natl. Acad. Sci. 112: 797-802. doi: 10.1073/pnas.1413650112. PMID: 25561561.

Laughlin, D.C., Joshi, C., van Bodegom, P.M., Bastow, Z.A., and Fulé, P.Z. 2012. A predictive model of community assembly that incorporates intraspecific trait variation. Ecol. Lett. 15: 1291-1299. doi: 10.1111/j.1461-0248. 2012.01852.x. PMID: 22906233.

Lavorel, S., and Garnier, E. 2002. Predicting changes in community composition and ecosystem functioning from plant traits: revisiting the Holy Grail. Funct. Ecol. 16: 545-556. doi: 10.1046/j.1365-2435.2002.00664.X.

Liu, Y., Dawson, W., Prati, D., Haeuser, E., Feng, Y., and van Kleunen, M. 2016. Does greater specific leaf area plasticity help plants to maintain a high performance when shaded?. Ann. Bot. 118: 1329-1336. doi: 10.1093/aob/mcw180. PMID: 27594648.

Madani, N., Kimball, J.S., Ballantyne, A.P., Affleck, D.L., Van Bodegom, P.M., Reich, P.B., et al. 2018. Future global productivity will be affected by plant trait response to climate. Sci. Rep. 8: 1-10. doi: 10.1038/s41598-018-21172-9. 
May, J.L., and Hollister, R.D. 2012. Validation of a simplified point frame method to detect change in tundra vegetation. Polar Biol. 35: 1815-1823. doi: 10.1007/s00300-012-1224-1.

McGill, B.J., Enquist, B.J., Weiher, E., and Westoby, M. 2006. Rebuilding community ecology from functional traits. Trends Ecol. Evol. 21: 178-185. doi: 10.1016/j.tree.2006.02.002. PMID: 16701083.

Mekonnen, Z.A., Riley, W.J., and Grant, R.F. 2018. Accelerated nutrient cycling and increased light competition will lead to 21st century shrub expansion in North American Arctic tundra. J. Geophys. Res. 123: 1683-1701. doi: 10.1029/2017JG004319.

Messier, J., McGill, B.J., and Lechowicz, M.J. 2010. How do traits vary across ecological scales? A case for trait-based ecology. Ecol. Lett. 13: 838-848. doi: 10.1111/j.1461-0248.2010.01476.x. PMID: 20482582.

Molau, U., and Mølgaard, P. 1996. International Tundra Experiment (ITEX) manual. 2nd ed. Danish Polar Center, Copenhagen, Denmark.

Muscarella, R., and Uriarte, M. 2016. Do community-weighted mean functional traits reflect optimal strategies?. Philos. T R. Soc. B. 283: 20152434. doi: 10.1098/rspb.2015.2434.

Myers-Smith, I.H., and Hik, D.S. 2017. Climate warming as a driver of tundra shrubline advance. J. Ecol. 106: 547-560. doi: 10.1111/1365-2745.12817.

Myers-Smith, I.H., Thomas, H.J., and Bjorkman, A.D. 2019. Plant traits inform predictions of tundra responses to global change. New Phytol. 221: 1742-1748. doi: 10.1111/nph.15592. PMID: 30444539.

Nadelhoffer, K.J., Giblin, A.E., Shaver, G.R., and Linkins, A.E. 1992. Microbial processes and plant nutrient availability in arctic soils. In Arctic ecosystems in a changing climate. Edited by F.S. Chapin, R.L. Jefferies, J.F. Reynolds, G.R. Shaver, J. Svoboda, and E.W. Chu. Academic Press. pp. 281-300.

Oberbauer, S.F., Elmendorf, S.C., Troxler, T.G., Hollister, R.D., Rocha, A.V., Bret-Harte, M.S., et al. 2013. Phenological response of tundra plants to background climate variation tested using the International Tundra Experiment. Philos T R Soc B. 368: 20120481. doi: 10.1098/rstb.2012.0481.

Oksanen, J., Blanchet, F.G., Friendly, M., Kindt, R., Legendre, P., McGlinn, D., et al. 2019. vegan: Community Ecology Package. R package version 2.5-6. Available from https://CRAN.R-project.org/package=vegan.

Parkhurst, D.F., and Loucks, O.L. 1972. Optimal leaf size in relation to environment. J. Ecol. 60: 505-537. doi: 10.2307/2258359.

Pearson, R.G., Phillips, S.J., Loranty, M.M., Beck, P.S., Damoulas, T., Knight, S.J., and Goetz, S.J. 2013. Shifts in Arctic vegetation and associated feedbacks under climate change. Nat. Clim. Chang. 3: 673-677. doi: 10.1038/nclimate1858.

R Core Team. 2018. R: A language and environment for statistical computing. R Foundation for Statistical Computing, Vienna, Austria.

Reich, P.B., Walters, M.B., and Ellsworth, D.S. 1992. Leaf life-span in relation to leaf, plant, and stand characteristics among diverse ecosystems. Ecol. Monogr. 62: 365-392. doi: 10.2307/2937116.

Reich, P.B., Ellsworth, D.S., Walters, M.B., Vose, J.M., Gresham, C., Volin, J.C., and Bowman, W.D. 1999. Generality of leaf trait relationships: a test across six biomes. Ecology, 80: 1955-1969. doi: 10.1890/0012-9658(1999)080[1955: GOLTRA]2.0.CO;2.

Saccone, P., Hoikka, K., and Virtanen, R. 2017. What if plant functional types conceal species-specific responses to environment? Study on arctic shrub communities. Ecology, 98: 1600-1612. doi: 10.1002/ecy.1817. PMID: 28317109.

Savile, D.B.O. 1972. Arctic adaptations in plants. California Botanical Society, Berkeley, California.

Schimel, J.P., Bilbrough, C., and Welker, J.M. 2004. Increased snow depth affects microbial activity and nitrogen mineralization in two Arctic tundra communities. Soil Biol. Biochem. 36: 217-227. doi: 10.1016/j.soilbio. 2003.09.008.

Schneider, C.A., Rasband, W.S., and Eliceiri, K.W. 2012. NIH Image to ImageJ: 25 years of image analysis. Nat. Methods, 9: 671-675. doi: 10.1038/nmeth.2089. PMID: 22930834.

Sellers, P.J. 1985. Canopy reflectance, photosynthesis and transpiration. Int. J. Remote Sens. 6: 1335-1372. doi: 10.1080/01431168508948283.

Soudzilovskaia, N.A., Elumeeva, T.G., Onipchenko, V.G., Shidakov, I.I., Salpagarova, F.S., Khubiev, A.B., et al. 2013. Functional traits predict relationship between plant abundance dynamic and long-term climate warming. Proc. Natl. Acad. Sci. 110: 18180-18184. doi: 10.1073/pnas.1310700110. PMID: 24145400.

Sultan, S.E. 2000. Phenotypic plasticity for plant development, function and life history. Trends Plant Sci. 5: 537-542. doi: 10.1016/S1360-1385(00)01797-0. PMID: 11120476.

Thomas, H.J., Myers-Smith, I.H., Bjorkman, A.D., Elmendorf, S.C., Blok, D., Cornelissen, J.H., et al. 2019. Traditional plant functional groups explain variation in economic but not size-related traits across the tundra biome. Glob. Ecol. Biogeogr. 28: 78-95. doi: 10.1111/geb.12783. PMID: 31007605.

Valladares, F., Gianoli, E., and Gómez, J.M. 2007. Ecological limits to plant phenotypic plasticity. New Phytol. 176: 749-763. doi: 10.1111/j.1469-8137.2007.02275.x. PMID: 17997761.

Venables, W.N., and Ripley, B.D. 2002. Modern Applied Statistics with S, 4th ed. Springer, New York. ISBN 0-38795457-0, Available from http://www.stats.ox.ac.uk/pub/MASS4/.

Wahren, C.H., Walker, M.D., and Bret-Harte, M.S. 2005. Vegetation responses in Alaskan arctic tundra after 8 years of a summer warming and winter snow manipulation experiment. Glob. Chang. Biol. 11: 537-552. doi: 10.1111/ j.1365-2486.2005.00927.x.

Wang, J., Rich, P.M., Price, K.P., and Kettle, W.D. 2004. Relations between NDVI and tree productivity in the central Great Plains. Int. J. Remote Sens. 25: 3127-3138. doi: 10.1080/0143116032000160499. 
Westoby, M., Falster, D.S., Moles, A.T., Vesk, P.A., and Wright, I.J. 2002. Plant ecological strategies: some leading dimensions of variation between species. Annu. Rev. Ecol. Syst. 33: 125-159. doi: 10.1146/annurev.ecolsys. 33.010802.150452.

Wilson, P.J., Thompson, K.E.N., and Hodgson, J.G. 1999. Specific leaf area and leaf dry matter content as alternative predictors of plant strategies. New Phytol. 143: 155-162. doi: 10.1046/j.1469-8137.1999.00427.x.

Yamori, W., Noguchi, K.O., Hikosaka, K., and Terashima, I. 2010. Phenotypic plasticity in photosynthetic temperature acclimation among crop species with different cold tolerances. Plant Physiol. 152: 388-399. doi: 10.1104/ pp.109.145862. PMID: 19880611. 